\title{
Research on Government Environmental Regulation Strategy in WEEE Based on Evolutionary Game Theory
}

\author{
Yichao Yuan ${ }^{1}$ and Kuiran Shi ${ }^{2}$ \\ ${ }^{1}$ Nanjing Tech University, Nanjing, 211800 \\ ${ }^{2}$ Nanjing Audit University, Nanjing, 211815
}

\begin{abstract}
With the progress of science and technology, a large number of waste electrical and electronic equipment (WEEE) not only poses a threat to the environment, but also causes serious waste of resources. It's necessary and practically significant for the governments environmental regulation to construct reverse logistics. This paper employs evolutionary game theory to study interaction of governments and firms and investigates the evolutionary stable strategies for firms using recycled wastes to produce new products. The paper shows that the rewards of government regulation, supervision costs, extraneous income of new products that produced by recycling WEEE, and subsidies of firms from the government for constructing the reverse logistics actively are key factors, which can affect the performance of the evolutionary game between the governments and firms. By controlling these factors, evolutionary stable strategies between firms and governments will close to the direction where firms constructing reverse logistics consciously and the governments reducing the proportion of supervision quickly and effectively.
\end{abstract}

Keywords-waste electrical and electronic equipment (WEEE); reverse logistics; evolutionary game; evolutionary stable strategy

\section{INTRODUCTION}

With the continuous progress of science and technology, mobile phones, computers and other electronic products are updating faster and faster. On the one hand, the impact of hazardous substances and pollutants contained in e-waste on the environment and public health has attracted increasing attention. On the other hand, there are many kinds of metal and nonmetal compounds in e-waste, whose resource value is very significant. The 13th Five-Year Plan has put forward to enhance environmental governance and to use the energy with high efficiency. The construction of closed loop eco industrial chain of recycling of waste electronic products is of vital importance. And its foundation is the government management department to supervise moderately after analyzing the current situation of the industry market. The governments should guide and urge producers to fulfill their social responsibilities in accordance with the inherent laws of the closed-loop eco industrial chain operation.

The construction of WEEE reverse logistics is an indispensable step in closed-loop supply chain management. Research on government regulation in China electronics firms establishing reverse logistics mainly focus on Extended Producer Responsibility (EPR) of the system level, there are few articles to guide the governments to take effective regulatory decision to supervise electronic firms to fulfill their social responsibilities through numerical simulation. Li etal ${ }^{[1]}$ pointed out that supply chain governance needs institutional mechanisms to guide stakeholders in the supply chain to make scientific decisions. Zhao Xiu-kun etal ${ }^{[2]}$ pointed out that corporate pollution control decisions depend mainly on the degree of interdependence between firms, production technology gap. Cao Jian etal ${ }^{[3]}$ pointed out that the government incentive contract can improve the level of recovery and remanufacturing of manufacturers better. Ogushi etal $^{[4]}$ pointed out that government regulations guide funds focused on the EPR project effectively, so that the EPR firms can get more financial support. Cheng Yong-wei ${ }^{[5]}$ pointed out that the governments should adjust the incentives according to the environmental loss coefficient, and achieve a win-win goal with the firms under the premise of ensuring the freedom of decision-making. Ma etal ${ }^{[6]}$ have studied consumers buying products in the closed-loop supply chain, and consumers benefit from buying new products regardless of whether the government has subsidies or not.

Game theory provides a suitable analytical tool for WEEE processing problems. The existing research focused on the necessity of building a WEEE reverse logistics, guarantee mechanism and policy suggestions, seldom considered the limited rationality of the governments and firms. Moreover, there are few articles to discuss how the governments and the firms adjust their strategies to make them evolve towards the target dynamically. Xiong Zhong-kai etal ${ }^{[7]}$ showed that different government incentives have different impacts on business recovery strategies. Zhang Xue-gang and Zhong $\mathrm{MaO}^{[8]}$ found that increasing penalties for polluting manufacturers and reducing dependence on income from polluting producers would help protect the environment. Zhu Qing-hua etal ${ }^{[9]}$ pointed out that the governments' rewards and punishments policies have a great impact on the construction of green supply chain. Wang Shi-lei ${ }^{[10]}$ studied the role of governments regulation in the implementation of reverse logistics through evolutionary game theory. Deng Liang etal ${ }^{[11]}$ used evolutionary game theory to point out that the development of manufacturing and logistics dual industries is an effective way to achieve the win-win situation between the two. It is also an effective industrial strategy in the economic transition period. This paper uses evolutionary game theory to construct a theoretical model, analyzes the strategy adjustment 
process of both the firms and the governments, and puts forward management suggestions on this basis.

\section{MOdEL BUILDING}

Consider two groups, namely the firms with WEEE and the local governments. There is a contradiction between the pursuit of profit maximization and the pursuit of a better environment. Therefore, firms have two measures for the disposal of WEEE. 1) Construct reverse logistics; 2) do not construct reverse logistics. Due to the large number of electronic firms in the area, the governments can not spend huge costs for real-time supervision. The government's strategy set is (regulation, non regulation). Inspired by the research methods of $\mathrm{Yu}$ Tao etal ${ }^{[12]}$, the basic assumptions are as follows:

Hypothesis 1: The proportion of firms groups decided to build reverse logistics is $x$, otherwise occupies $1-x$. In the governments groups, the proportion of adopting the supervision strategy is $y$, and the proportion of the non supervision strategy is $1-y$.

Hypothesis 2: The cost of constructing reverse logistics is $C_{m}$, such as the price paid by the firms to the consumers, the cost of treatment or regeneration the WEEE for firms. As firms build reverse logistics actively, or because of government regulation timely, comprehensive benefits $R$ are brought to society, such as improvement of resource recovery rate and a marked reduction in environmental pollution. The benefits of manufacturing new products by recycling WEEE is $P_{r}$, the benefits of manufacturing new products by repurchasing raw materials is $P_{n}$. Obviously, $P_{r}>P_{n}$. Because firms have increased the comprehensive income by saving materials.

Hypothesis 3: The government chooses to perform its supervisory duties and the regulatory cost is $C_{g}$, including fees paid by the government to third parties for service and supervisor cost. Regulatory rewards received is $S_{g}$. This is because the central government will bring WEEE recycling level into the performance evaluation of local government. If the local governments take the laissez faire measures for the firms, this has resulted in social losses (environmental pollution). The government needs to pay for the remediation costs $C_{r}$.

Hypothesis 4: For the firms that the reverse logistics are not built, the governments imposed a WEEE treatment fund $S_{a}$ on it. For some firms that respond to the government's call positively, and build reverse logistics actively, the governments give WEEE subsidies $S_{b}$.

According to the above hypotheses, the game payoff matrix is shown in table 1 :
TABLE I. PAYOFF MATRIX OF THE GOVERNMENTS-FIRMS GAME

\begin{tabular}{|c|c|c|c|}
\hline & \multicolumn{2}{|l|}{ Governments } \\
\hline & & regulation & $\begin{array}{l}\text { Non regulation } \\
1-y\end{array}$ \\
\hline \multirow{2}{*}{ Firms } & $\begin{array}{l}\text { build } \\
x\end{array}$ & $\begin{array}{l}P_{r}+S_{b}-C_{m} \\
S_{g}-C_{g}-S_{b}+R\end{array}$ & $\begin{array}{l}P_{r}+S_{b}-C_{m} \\
-S_{b}+R\end{array}$ \\
\hline & $\begin{array}{l}\text { No } \\
\text { build } \\
1-x\end{array}$ & $\begin{array}{l}P_{n}-S_{a} \\
S_{g}-C_{g}-C_{r}+R+S_{a}\end{array}$ & $P_{n},-C_{r}$ \\
\hline
\end{tabular}

\section{EVOlUtionARY GAME MODEL ANALYSIS}

A. The Balance Point of Evolution Process

For firms, the average expected payoff:

$$
\bar{U}_{1}=x U_{1 d}+(1-x) U_{1 n}
$$

For governments, the average expected payoff:

$$
\bar{U}_{2}=y U_{2 d}+(1-y) U_{2 n}
$$

According to the related theory of evolutionary game we can get the replicated dynamic equation as follows:

$$
\begin{aligned}
& \dot{x}=\frac{d x}{d t}=x\left(U_{1 d}-\overline{U_{1}}\right)=x(1-x)\left(P_{r}+S_{b}-C_{m}-P_{n}+y S_{a}\right) \\
& \dot{y}=\frac{d y}{d t}=y\left(U_{2 d}-\overline{U_{2}}\right)=y(1-y)\left(-x S_{a}+S_{g}-C_{g}+R+S_{a}-x R\right)
\end{aligned}
$$

A two-dimensional dynamic system (J) can be obtained by differential equations (3) and (4):

$$
\left\{\begin{array}{l}
\frac{d x}{d t}=x\left(U_{1 d}-\overline{U_{1}}\right)=x(1-x)\left(P_{r}+S_{b}-C_{m}-P_{n}+y S_{a}\right) \\
\frac{d y}{d t}=y\left(U_{2 d}-\overline{U_{2}}\right)=y(1-y)\left(-x S_{a}+S_{g}-C_{g}+R+S_{a}-x R\right)
\end{array}\right.
$$

For systems (J), by $\frac{d x}{d t}=0$ and $\frac{d y}{d t}=0$, we can obtain the following conclusions.

Proposition 1:Dynamic system (J) has five equilibria, namely $(0,0),(0,1),(1,0),(1,1)$ and $\left(x_{M}, y_{M}\right)$.

$$
x_{M}=\frac{S_{g}-C_{g}+R+S_{a}}{S_{a}+R}, y_{M}=\frac{C_{m}+P_{n}-P_{r}-S_{b}}{S_{a}} .
$$

\section{B. Stability Analysis of Equilibrium}

According to Friedman ${ }^{[13]}$, a method for judging the stability of dynamic systems is proposed. The resulting 
Jaconbian matrix is $J=\left[\begin{array}{ll}\frac{\partial \dot{x}}{\partial x} & \frac{\partial \dot{x}}{\partial y} \\ \frac{\partial \dot{y}}{\partial x} & \frac{\partial \dot{y}}{\partial y}\end{array}\right]=\left[\begin{array}{ll}a_{11} & a_{12} \\ a_{21} & a_{22}\end{array}\right]$

$a_{11}=(1-2 x)\left(P_{r}+S_{b}-C_{m}-P_{n}+y S_{a}\right) \quad, \quad a_{12}=x(1-x) S_{a} \quad$,

$a_{21}=-y(1-y)\left(S_{a}+R\right)$

$a_{22}=(1-2 y)\left(-x S_{a}+S_{g}-C_{g}+R+S_{a}-x R\right)$

For convenience, the specific values of the above Local equilibrium points have been calculated, as shown in Table 2 below.

TABLE II. RESULTS FOR DIFFERENT FIXED POINTS

\begin{tabular}{lllll}
\hline Equilibrium & $a_{11}$ & $a$ & $a_{21}$ & $a_{22}$ \\
\hline$(0,0)$ & $P_{r}+S_{b}-C_{m}-P_{n}$ & 0 & 0 & $S_{g}-C_{g}+R+S_{a}$ \\
$(0,1)$ & $P_{r}+S_{b}-C_{m}-P_{n}+S_{a}$ & 0 & 0 & $-S_{g}+C_{g}-R-S_{a}$ \\
$(1,0)$ & $-P_{r}-S_{b}+C_{m}+P_{n}$ & 0 & 0 & $S_{g}-C_{g}$ \\
$(1,1)$ & $-P_{r}-S_{b}+C_{m}+P_{n}-S_{a}$ & 0 & 0 & $-S_{g}+C_{g}$ \\
& & & & \\
$\left(\mathrm{XM}_{\mathrm{M}}, \mathrm{y}_{\mathrm{M}}\right)$ & 0 & A & 0 \\
\hline
\end{tabular}

$$
\begin{gathered}
A=\frac{S_{g}-C_{g}+R+S_{a}}{S_{a}+R}\left(1-\frac{S_{g}-C_{g}+R+S_{a}}{S_{a}+R}\right) S_{a} \\
B=\frac{C_{m}+P_{n}-P_{r}-S_{b}}{S_{a}}\left(\frac{C_{m}+P_{n}-P_{r}-S_{b}}{S_{a}}-1\right)\left(S_{a}+R\right)
\end{gathered}
$$

From table 2, we can see that there is a contradiction between the local equilibrium points and the trace condition $a_{11}+a_{22}=0$, Therefore, local equilibrium $\left(x_{M}, y_{M}\right)$ is not an evolutionarily stable strategy. We can find the values of the determinant and trace of the other 4 local equilibrium points about the Jaconbian matrix, and then we can judge the local stability.

Proposition 2: (1)When $\quad S_{g}-C_{g}+R+S_{a}<0 \quad$ and $C_{m}+P_{n}-S_{a}<P_{r}+S_{b}<C_{m}+P_{n} \quad$ or $\quad S_{g}-C_{g}+R+S_{a}<0 \quad$ and $P_{r}+S_{b}<C_{m}+P_{n}-S_{a}$, the ESS of the system $(\mathrm{J})$ is $(0,0)$.

(2)When $C_{g}<S_{g}$ and $C_{m}+P_{n}-S_{a}<P_{r}+S_{b}<C_{m}+P_{n}$ or $C_{g}<S_{g}$ and $P_{r}+S_{b}>C_{m}+P_{n}$, the ESS of the system (J) is $(1,1)$.

Proof: The following is the proof of conclusions (1). Conclusions (2) can be obtained by the same way. For dynamic systems (J), We can get two cases by calculating the Jaconbian matrix. Similarly, the following propositions 3 and 4 can be obtained.
TABLE III. EVOLUTIONARY STABILITY OF FIXED POINTS FOR $S_{g}-C_{g}+R+S_{a}<0$ AND $C_{m}+P_{n}-S_{a}<P_{r}+S_{b}<C_{m}+P_{n}$

\begin{tabular}{clll}
\hline Equilibrium point & trJ & detJ & stability \\
\hline$(0,0)$ & - & + & ESS \\
$(0,1)$ & + & + & Unstable point \\
$(1,0)$ & Uncertain & - & saddle point \\
$(1,1)$ & Uncertain & - & saddle point \\
\hline
\end{tabular}

TABLE IV. EVOLUTIONARY STABILITY OF FIXED POINTS FOR $S_{g}-C_{g}+R+S_{a}<0$ AND $P_{r}+S_{b}<C_{m}+P_{n}-S_{a}$

\begin{tabular}{clll}
\hline Equilibrium point & trJ & detJ & stability \\
\hline$(0,0)$ & - & + & ESS \\
$(0,1)$ & Uncertain & - & saddle point \\
$(1,0)$ & Uncertain & - & saddle point \\
$(1,1)$ & + & + & Unstable point
\end{tabular}

Proposition 3: (1) when $P_{r}+S_{b}-C_{m}-P_{n}+S_{a}<0$ and $0<C_{g}-S_{g}<R+S_{a}$ or when $P_{r}+S_{b}-C_{m}-P_{n}+S_{a}<0$ and $C_{g}-S_{g}<0$, the ESS of the system $(\mathrm{J})$ is $(0,1)$;

(2) when $-P_{r}-S_{b}+C_{m}+P_{n}<0$ and $0<C_{g}-S_{g}<S_{a}+R$, or when $-P_{r}-S_{b}+C_{m}+P_{n}<0$ and $C_{g}-S_{g}>S_{a}+R$, the ESS of the system (J) is $(1,0)$.

Proposition 4: when $0<C_{g}-S_{g}<R+S_{a} \quad$ and $C_{m}+P_{n}-S_{a}<P_{r}+S_{b}<C_{m}+P_{n}$, the system (J) does not exist ESS.

\section{CONCLUSION}

In the context of an increase in the index of used electronic products. This paper gives full consideration to the behavior games between the governments and the firms, the evolutionary stability strategies are obtained under different conditions through the construction of the two groups evolutionary game model. It is considered that the reward of government regulation, the cost of supervision and the profit of firms' recycling of waste electronic products are the key factors that influence the evolutionary game behavior of governments and firms. As long as the profits that firms received by recycling WEEE and reproduction are big enough, firms can build reverse logistics consciously on the basis of the pursuit of maximum benefits and the governments can also reduce regulatory costs, thus improving the overall social welfare greatly.

The research conclusions of this paper has some enlightenment: When the firms construct the reverse logistics, the cost is obviously lower than the sum of the additional profits of the reverse logistics and the subsidy provided by the government. For the purpose of profit maximization, firms have great incentive to build reverse logistics. The cost of government regulation is far greater than the sum of the 
benefits to society and its rewards, the governments will reduce the proportion of supervision gradually and the overall social welfare increased in this case.

In this article, we give four propositions and some parameters. Evolutionary stable strategies between firms and governments will gradually close to the direction quickly and effectively where firms will construct reverse logistics consciously and the governments will reduce the proportion of supervision by controlling these factors.

Further research can examine the government's different level of regulation,. There are also interesting questions about the Cournot and Stackelberg game between the environmental protection firms in oligopoly.

\section{ACKNOWLEDGMENT}

This work was supported by National Natural Science Foundation of China (Grant No. 71301073), the National Social Science Foundation of China (Grant No. 16FGL011), Jiangsu provincial key disciplines of Applied Economics (Grant No. Su Zhengban Series No. [2014]37)and Postgraduate Practical Innovation Program in JiangSu(SJCX17_0302).

\section{REFERENCES}

[1] LI Y, ZHAO X, SHI D, et al. Governance of sustainable supply chains in the fast fashion industry[J]. European Management Journal, 2014, 32(5):823-836.

[2] ZHAO Xiu-kun, LI Yong-jian, Shi Dan. Game analysis of supply chain governance mechanism based on EPR [J]. Journal of Systems Engineering, 2015, 30(2):231-239.

[3] CAO Jian, HU Qiang, WU Xiao-bo, ZHOU Gen-gui. Design of incentive contract between government and manufacturer based on EPR system [J]. System Engineering Theory and Practice, 2013, 33(3): 610621.

[4] Ogushi Y, Kandlikar M. Assessing Extended Producer Responsibility Laws in Japan[J]. Environmental Science \& Technology, 2007, 41(13):4502-4508.

[5] CHENG Yong-wei. The game between government and manufacturer based on EPR system [J]. Soft Science, 2011, 25(11):78-81.

[6] Ma W M, Zhao Z, Ke H. Dual-channel closed-loop supply chain with government consumption-subsidy[J]. European Journal of Operational Research, 2013, 226(2):221-227.

[7] XIONG Zhong-kai, HUANG De-bin, XIONG Yu. Closed loop supply chain model based on Remanufacturing under the condition of government incentives [J]. Industrial Engineering Journal, 2011, 14(2):1-5.

[8] ZHANG Xue-gang, ZHONG Mao-chu. Research about Government Regulation and the Firm Environment Pollution under Perspective of Game Theory [J]. China Population, Resources and Environment, 2011, 21(2):31-35.

[9] ZHU Qing-hua, DOU Yi-jie. An Evolutionary Model between Governments and Core-firms in Green Supply Chains [J]. System Engineering Theory and Practice, 2007, 27(12):85-89.

[10] WANG Shi-lei, YAN Guang-le, LI Zhen. Analysis of evolutionary game on reverse logistics [J]. Journal of Systems Engineering, 2010, 25(4): 90-95.

[11] DENG Liang, ZOU Zhao-xi. Manufacturing and Logistics Linkage Development Research in the Perspective of Evolutionary Cooperative Game Model[J]. Research on Economics and Management, 2014(8):6065.

[12] YU Tao, LIU Chang-yu. The Analysis of Evolution Game Model and Simulation between Governments and the Third-Party in Product Quality Regulation[J]. Chinese Journal of Management Science, 2016,24(6): 90-96.
[13] Friedman D. Evolutionary Games in Economics[J].Econometrica, 1991, 59(3):637-666. 